462 EVALUATION OF ARTERIAL HYPERTENSION AND OTHER CARDIOVASCULAR RISK FACTORS. (FRICOR PROGRAM). A LOGISTICS COMPANY. (CORREO OFICIAL DE LA REPUBLICA ARGENTINA)

${ }^{1} \mathrm{M}$ Depsztok*, ${ }^{2} \mathrm{~J}$ Cesar, ${ }^{3} \mathrm{H}$ Ortiz Maldonado. ${ }^{1}$ Occupational Health Phyisician. Chief. CORREO OFICIAL, Buenos Aires, Argentina; ${ }^{2}$ Occupational Health Phyisician. Staff. CORREO OFICIAL, Buenos Aires, Argentina; ${ }^{3}$ Occupational Health Physician. Medical Manager. CORREO OFICIAL, Buenos Aires, Argentina

\subsection{6/oemed-2018-ICOHabstracts.220}

Introduction An evaluation of the employee population of the CORREO OFICIAL (LOGISTICS COMPANY) from August 2012 to April 2017 was conducted, with a primary objective of early detection of high blood pressure (HBP) and a second objective of analysing the prevalence of other cardiovascular risk factors. A subset was established to analyse the results.

Methods Prospective survey study of 16900 employees of the CORREO OFICIAL. The sample was conducted on patients who attended the External Office of Occupational Health with different pathologies. 3000 employees were examined and divided into two groups: Mail Distributors (MD) and Administrative Office Workers (AOW). Personal data (age and gender) was recorded for each patient and follow-ups were done by phone. HBP was differentiated as either KNOWN (KHBP) or UNKNOWN (UHBP).

Results 23\% of the population studied suffers from HBP. Mail Distributors: KHBP: 9.1\%. UHBP: 8.4\%. Administrative Office Workers: KHBP: 17.7\%. UHBP:11.2\%. Other risk factors: Smoking. MD: 34\%, AOW: 25,7\%; Diabetes. MD:1,9\%, AOW: 3,8\%; Dyslipidemias. MD: 8\%, AOW: 18,6\%; Sedentary Lifestyle. MD: 0\%, AOW: 65\%; Overweight/Obese. MD: 48,8\%, AOW: 42,5\%

Conclusion The importance of tests like these which detect unknown HBP and relate it back to other cardiovascular risks factors is clear. A high prevalence of overweight/obese individuals was detected in both groups, particularly in the Mail Distributors whose job demands intense physical activity. The sedentary employees demonstrate higher levels of dyslipidemias. The low cost and simplicity of this study makes its implementation in Occupational Health Services highly recommendable worldwide.

\section{STANDARDISED REPORTING OF OCCUPATIONAL HEALTH AND SAFETY IMPACTS}

Laura Espinach*. Standards Division - Global Reporting Initiative, Amsterdam, Netherlands

10.1136/oemed-2018-ICOHabstracts.221

Introduction The GRI Sustainability Reporting Standards are used by more than 4000 organisations in over 90 countries to report on their economic, environmental and social impacts including occupational health and safety impacts. The GRI Standards are referenced in policy and regulation in more than 50 countries, and by nearly 40 stock exchanges worldwide.

GRI is currently reviewing its OSH reporting standard to align it with internationally-agreed best practice and recent developments in $\mathrm{OSH}$ management and reporting practice.

The project will address important topics such as the reporting of occupational illnesses, workers' access to occupational health services, and workplace health promotion.
Methods The GRI Standards are issued by the Global Sustainability Standards Board (GSSB), GRI's independent standardsetting body. The work follows the GSSB's Due Process Protocol, which ensures a transparent process and provides many opportunities for input from diverse stakeholders.

A multi-stakeholder expert Working Group has been formed to revise the content, with leading experts from the ILO, the Centre for Safety and Health Sustainability, IOSH, and U.S. OSHA, among many others.

The draft standard will be published for public comment between August and October 2017. The final standard is expected to be published March-April 2018.

Result This process will deliver a set of best practice metrics for organisations around the world to report on their $\mathrm{OSH}$ impacts in a standardised way.

Conclusion The new standard will be of significant interest to Congress participants, with the potential to affect the day-today work of many. Featuring the input of leading organisations in $\mathrm{OSH}$, it will represent a credible attempt to standardise the way that organisations worldwide communicate about their OSH impacts. Ultimately, the transparency created by such a standard is intended to lead to positive change, thus contributing to sustainable development. For these reasons, GRI would value the opportunity to present the standard at the Congress.

\section{SYSTEMATIC REVIEW EVIDENCE IN ONE MINUTE OR LESS}

D Van Eerd*, U Vu, K Buccat, E Irvin, K Cullen, C Moser. Institute for Work and Health, Toronto, Canada

\subsection{6/oemed-2018-ICOHabstracts.222}

Introduction Getting research evidence to knowledge users is a challenge. The Institute for Work and Health (IWH) initiated a systematic review program in 2004 to synthesise scientific literature on prevention of workplace injuries and disability. IWH systematic review products include 2-3 page lay summaries (called Sharing Best Evidence). The lay summaries are popular but are considered long by some knowledge users. Our objective was to produce and post short videos that summarise key findings of systematic reviews in one minute or less.

Methods Video shorts are created by a multi-disciplinary team including a researcher, a video producer and a communications expert. The video shorts are based on high quality research (e.g. systematic review findings). Key messages are created in consultation with stakeholders. The production process begins with a storyboard (frame-by-frame outline). Development requires careful attention to style, pacing, tone, clarity, visual interest and audience appeal. Videos are tested with members of the target audience before being posted. Video shorts typically take about four weeks to complete.

Results Two, 1 min videos were developed by IWH made to reach busy stakeholders with evidence they need in their work. The first video, posted since October 2016, is popular receiving over 1100 hits to date.

Length: Videos are kept as short as possible, less than one minute.

Format: No voice-overs are used. Simple graphics, images, text and short video clips are used, with instrumental background music. 